\title{
Microbial Fuel Cell Wastewater Treatment of Copper-Based Heavy Metal Sensor
}

\author{
Wang Ling ${ }^{1}$, Wu Yining ${ }^{1,2, ~ *, ~ G a o ~ Y a ~}{ }^{1}$ \\ ${ }^{1}$ School of Municipal and Environmental Engineering, Harbin Institute of Technology, Harbin, China \\ ${ }^{2}$ State Key Laboratory of Urban WaterResource and Environment, Harbin Institute of Technology, Harbin, China
}

\section{Email address:}

18846828450@163.com (Wang Ling),wynhit@sina.com (Wu Yining), 1162541419@qq.com (Gao Ya)

${ }^{*}$ Corresponding author

\section{To cite this article:}

Wang Ling, Wu Yining, Gao Ya. Microbial Fuel Cell Wastewater Treatment of Copper-Based Heavy Metal Sensor. Science Discovery. Vol. 5, No. 3, 2017, pp. 199-204. doi: 10.11648/j.sd.20170503.17

Received: February 18, 2017; Accepted: March 16, 2017; Published: May 11, 2017

\begin{abstract}
The research is based on the single-chamber microbial fuel cell, with the presence of oxygen, we vary the concentration gradient of copper ions, and observe the changes of the electrochemical parameters to explore the practical application of microbial fuel cells as heavy metal sensors. It was found that: the single-chamber microbial fuel cell, the outer barrier of 30min real-time voltage $1000 \Omega, 100 \mathrm{Mmpbs}$, under $1000 \mathrm{mg} / \mathrm{LCOD}$, case, data acquisition card collection, with the change of the concentration gradient, linear development, polarization curves the measured voltage and power density, showing trends $\mathrm{X}^{2}$ by multimeter collected anode and cathode potentials, also showed a trend $\mathrm{X}^{2}$, in order at the same time, through the environment, $\mathrm{COD}, \mathrm{PH}$, and other factors, be optimization process, resulting in more accurate variation for the practical application of microbial fuel cells, providing new ideas.
\end{abstract}

Keywords: Microbial Fuel Cell, Heavy Metal Sensor, Copperions, Trend

\section{基于微生物燃料电池测试铜离子在重金属生物传感器的研究}

王岭 ${ }^{1}$, 吴忆宁 ${ }^{1,2^{*}}$, 高雅 ${ }^{1}$

${ }^{1}$ 市政环境工程学院, 哈尔滨工业大学, 哈尔滨, 中国

${ }^{2}$ 城市水资源和水环境国家重点实验室, 哈尔滨工业大学, 哈尔滨, 中国

邮箱

18846828450@163.com（王岭），wynhit@sina.com（吴忆宁），1162541419@qq.com（高雅）

摘要: 本文以单室的微生物燃料电池为基础, 通过设置铜离子的不同浓度梯度来研究电化学参数的响应, 从而为生物 燃料电池在重金属传感器方面的应用奠定基础。实验发现: 单室的微生物燃料电池 ( SMFC), 在外阻为 $1000 \Omega, 100 \mathrm{Mmpbs}$, $1000 \mathrm{mg} / \mathrm{LCOD}$ 的情况下, 分别测量其极化曲线和功率密度, 阴阳极电位, 30min的实时电压, 并进行电化学参数的表征, 结果发现数据采集卡所采集的 $30 \mathrm{~min}$ 实时电压, 随着浓度梯度的变化, 呈线性的发展, 同时, 极化曲线所测得的电压和 功率密度, 呈 $X^{2}$ 的变化趋势, 另外, 通过万用表所采集的阴阳极电位, 同样也呈 $X^{2}$ 的趋势, 这个结果为微生物燃料电 池的实际应用, 提供新的思路。

关键词：微生物燃料电池，重金属传感器，铜离子，变化趋势 


\section{1. 引言}

微生物燃料电池（Microbial Fuel Ce11, MFC）是在 阳极利用产电微生物, 降解污水中的有机污染物, 同时产 生电子, 电子通过介质到达阳极表面, 经由闭合回路到达 阴极, 被阴极的还原性物质所利用, 产生电能 [1]。微生 物燃料电池是一种新型的生物质能源, 在去除有机污染物 的同时, 可以产生电能 [2], 缓解我国的能源危机。目前, 微生物燃料电池的另一个研究方向是对于重金属离子的 去除 [3-5], 而且对于某些重金属离子去除率很高, 比如 等 $[6-12]$ 。

微生物燃料电池的目前发展, 无论是处理重金属废水, 还是产生能源, 均由于自身体积的限制, 很难进行中试, 或进一步应用于实践, 而本实验为了开拓其发展, 摆脱试 验阶段, 探究其作为生物传感器 [13-15]的可能性, 它无 需物理或化学的转换器, 并同时具备生物传感器的特点, 是一种易操作的在线监测生物传感器, 本文利用微生物燃 料电池自身的特性, 通过改变其铜离子的浓度, 观察电化 学参数的变化规律, 研究它在重金属传感器 [16]方面的应 用。

\section{2. 材料和方法}

\section{1. 材料和仪器}

数据采集卡 (PISO-813, 泓格, 台湾), 分光光度计 (UV-6000, METASH, China), 电化学工作站（CH1660C, 上海辰华仪器有限公司), 可调式变阻箱 (ZX21型实验室 直流电阻箱, 上海立春静蜢仪器有限公司), 数字万能表 (VC9808+, 深圳胜利万用表)，化学药品均为实验用的 分析试剂。

\section{2. 实验装置}

实验装置如下图1:

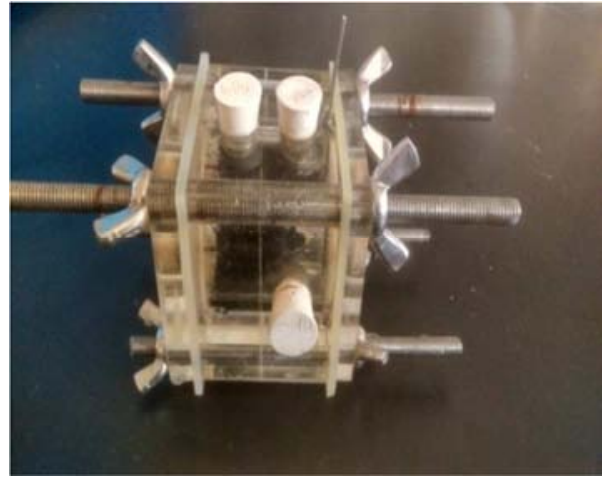

图1 实验装置图。

采用容积为 $28 \mathrm{~m} 1$ 单室的微生物燃料电池, 阳极为碳 刷, 阴极为Pt/C的碳布, 并涂有防水层, 外接电阻为 1000 $\Omega$, 在 $100 \mathrm{mMPBS}$ 、乙酸钠 $1.28 \mathrm{~g} / \mathrm{L}$ 、初始 $\mathrm{pH}=6.4$ 、温度 $35 \pm 1^{\circ} \mathrm{C}$ 的条件下启动, 里面的污泥来自于UASB的成熟污
泥, 整个装置通过导线与数据采集卡进行连接, 来记录产 生的电压。

\section{3. 实验方法}

本文对于铜离子的浓度梯度, 分为 $1-12 \mathrm{mg} / 1$, 对反应 器进行实验, 其间通过数据采集卡, 进行电压的记录; 通 过变电阻法, 测量极化曲线和功率密度曲线的绘制; 采用 万用表和参比电极, 记录其阴阳极电位; 依据国家标准对 COD和库伦效率进行测量; 采用分光光度法, 对铜离子的 去除进行检测。

\section{3. 结果与讨论}

\section{1. 单室微生物燃料电池 (SMFC) 的启动和驯化}

如图2A所示, SMFC启动运行了 $500 \mathrm{~h}$, 电压值达到 $0.56 \pm 0.01 \mathrm{~V}$, 用 $1 \mathrm{mg} / \mathrm{L}$ 的铜离子进行驯化, 由电压图可见, 刚开始加入的铜离子足以满足微生物内部微量元素的需 求, 电压有所提升。在启动和驯化的整个过程中, 对极化 曲线和功率密度曲线、电极电位以及 $\mathrm{COD}$ 去除的测量, 作 为参比数据, 从图2 (a) (c) 可知反应器启动良好, 电 化学参数稳定, COD去除率高, (b) 反应反应器的产电性 能正常, 可以进行下一步的实验。

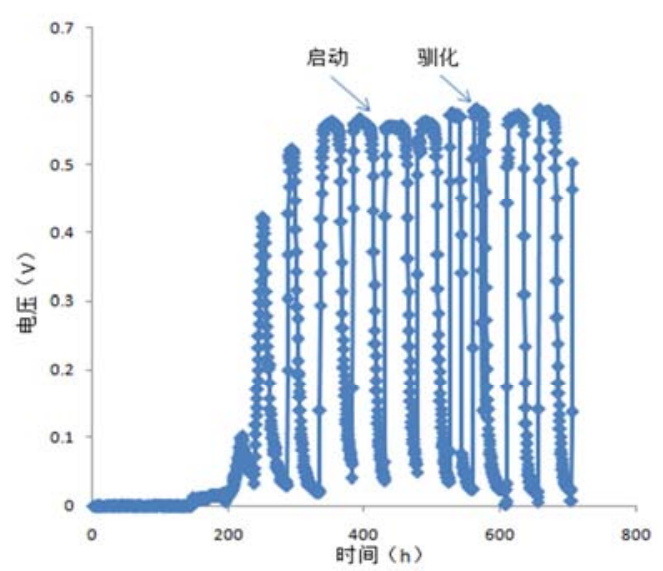

图2（a）30min电压图。

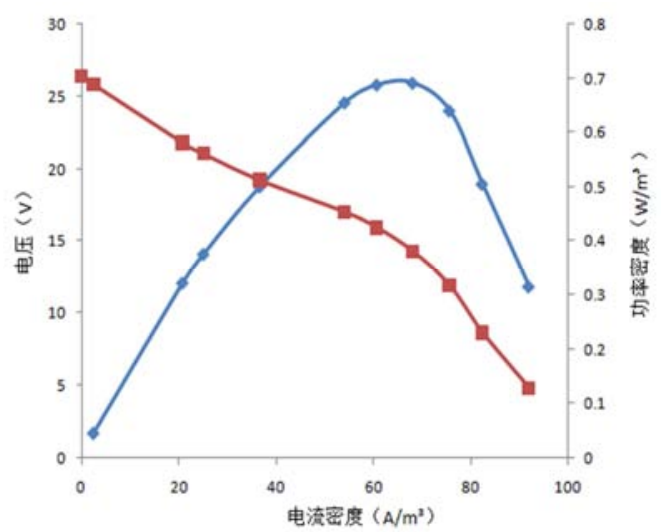

图2（b）极化功率图。 


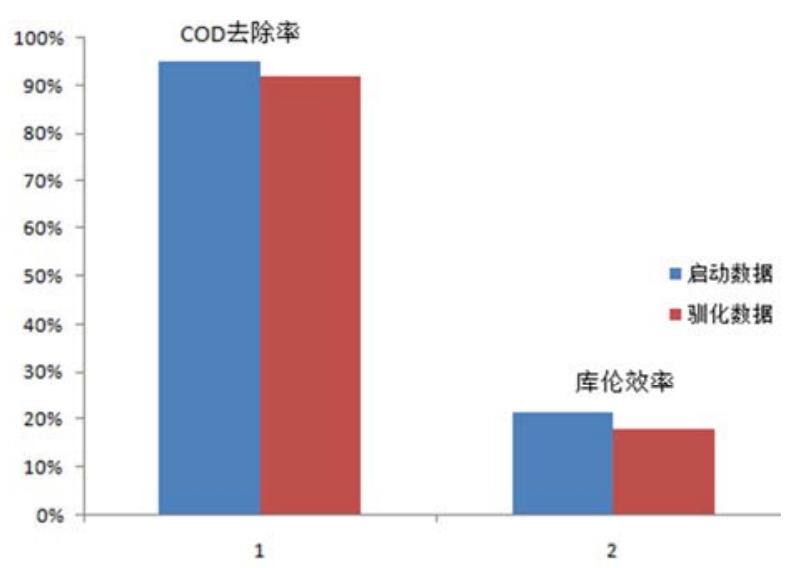

图2（c） CE和COD去除率。

\section{2. 不同浓度铜离子-电化学参数的变化趋势}

本实验把铜离子浓度按照不同的浓度梯度, 分别向反 应器中投加, 观察其电化学的变化, 如下图3 (a) - (e) 所示。

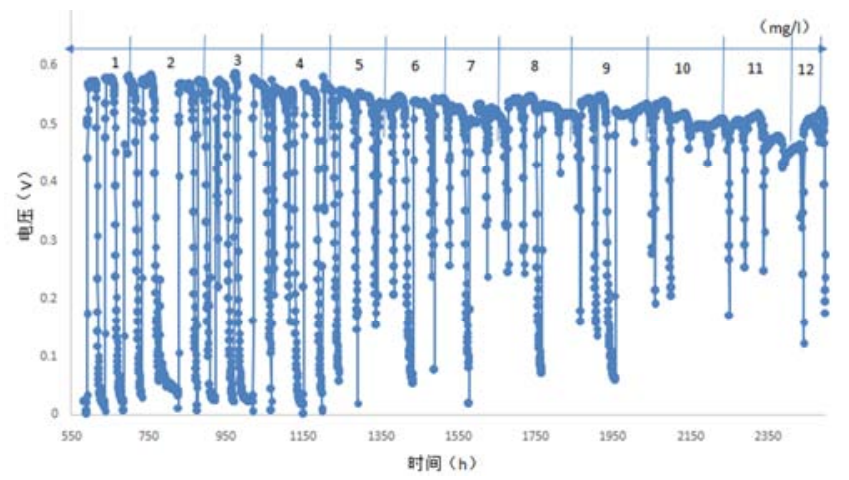

图3（a）30min电压图。

从图（a）电压图可知, 在整体铜离子浓度梯度的观 察过程中，电压有明显的变化，基本呈线性趋势，而且铜 离子的毒害作用, 一直处于微生物可以接受的范围内，微 生物通过自身的降解作用以及产生相应的酶, 使机体保持 正常的活性, 维持反应器的正常运行。

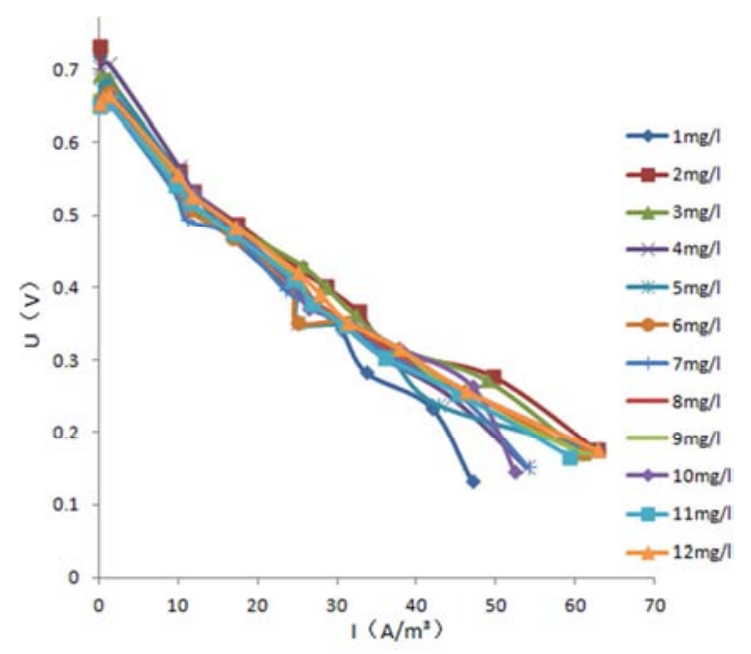

图3（b）极化曲线。

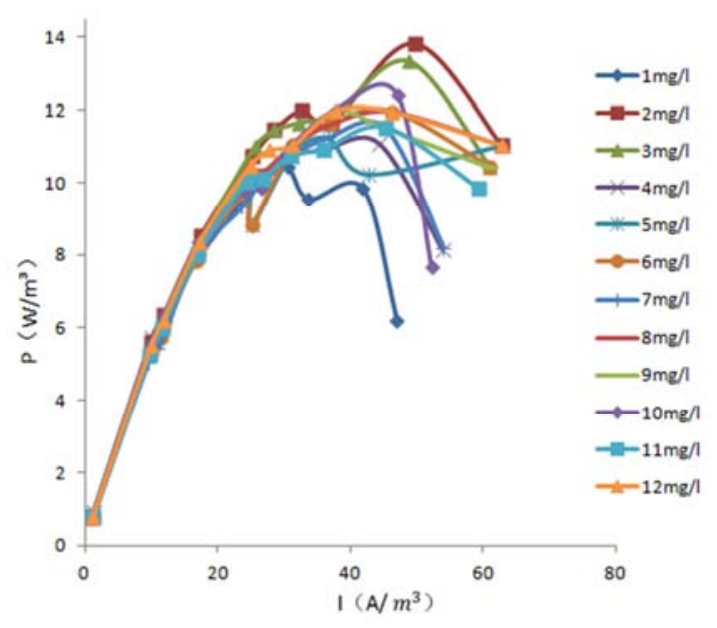

图3（c）功率密度曲线。

图（b）极化曲线反应, 在整个运行的过程中, 随着 铜离子浓度的升高, 电流密度或功率密度呈现出一个先上 升后下降的过程。微生物在降解有机物初期, 微生物通过 自身的新陈代谢作用，降低铜离子的毒害作用，维持其相 应的活性, 随着浓度的升高, 毒害作用的加重, 影响了微 生物自身酶蛋白的活性, 导致其电子的传质速率降低, 电 流密度以及功率密度也相应的降低。

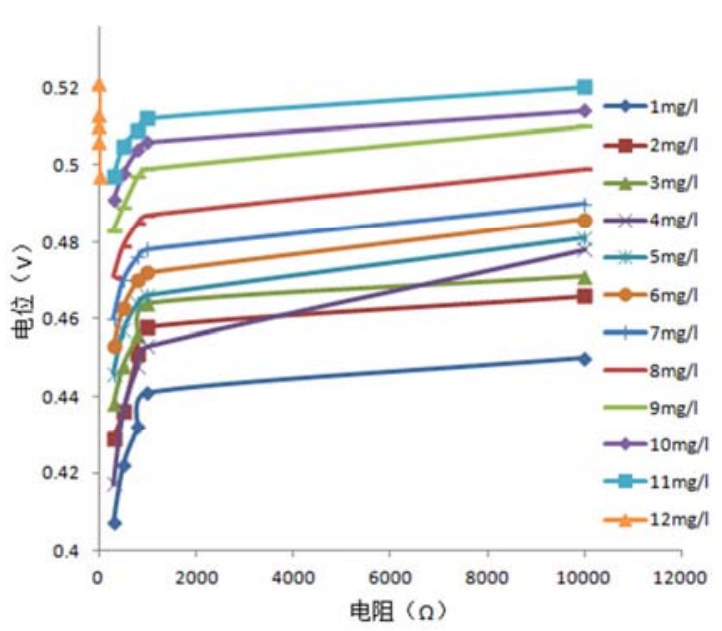

图3（d）阳极电位图。

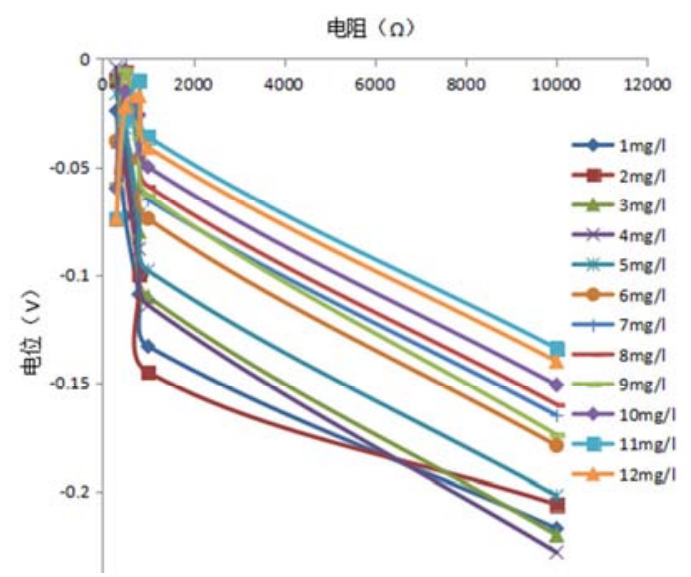

图3（e）阴极电位图。 
相对于其上的实时电压变化及其功率密度和电流密 度等, 阴阳极电位的变化似乎更能凸显出反应器的状态与 浓度的变化关系, 从图形看更加的直观, 而且从微生物燃 料电池整个的反应机理, 重金属离子浓度的变化, 将直接 影响其微生物的生命活动, 而微生物附着在阳极碳刷上, 阴阳极电位的变化更直接。

为了测试其反应器的状态, 在通过一系列的铜离子的 浓度梯度后, , 测定了以下数据, COD的去除率, 都在 $90 \pm 9 \%$ 的范围内, $\mathrm{Cu}$ 的去除率的区间为 $90 \pm 8 \%$, 反映其在整个过 程中反应器运行良好, 微生物的活性周期一直处于稳定的 状态, 如下图所示。

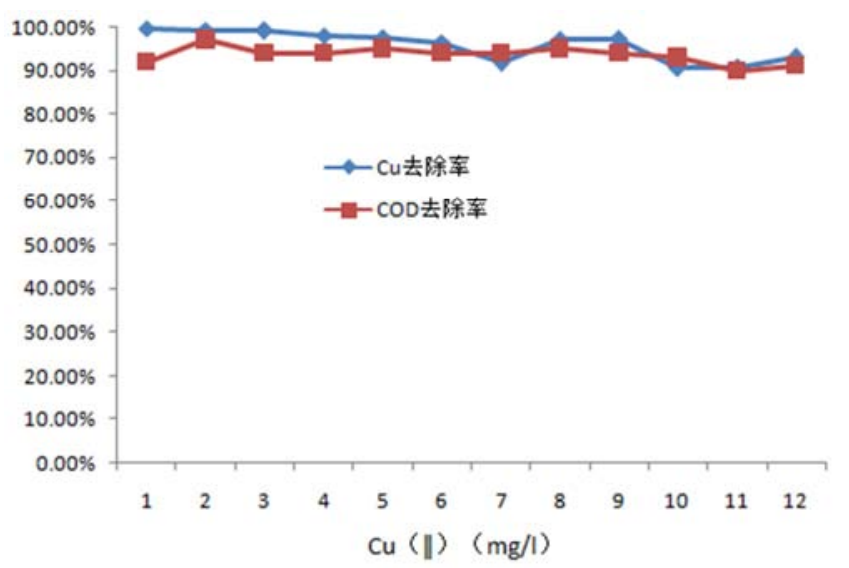

图4 Cu, COD去除率图。

\section{3. 电化学参数的表征}

以下为电化学层面的响应, 从 (a) - (f) 可知, 数 据采集卡所测得实时电压呈线性的变化, 方程式为 $\mathrm{Y}=-0.005 \mathrm{X}+0.542$, 其中判定系数 $=0.994$, 判定系数代表 现有数据和方程式 (趋势线) 的拟合度, 越接近 1 说明拟 合度越好。其余的参数电流密度, 功率密度, 阴阳极电位 等都呈现 $X^{2}$ 的关系, 而且整体的趋势也符合, 彼此直接的 换算关系, 从生物传感器简单、便捷的角度来讲, 实时电 压可以作为本研究的电化学表征参数。

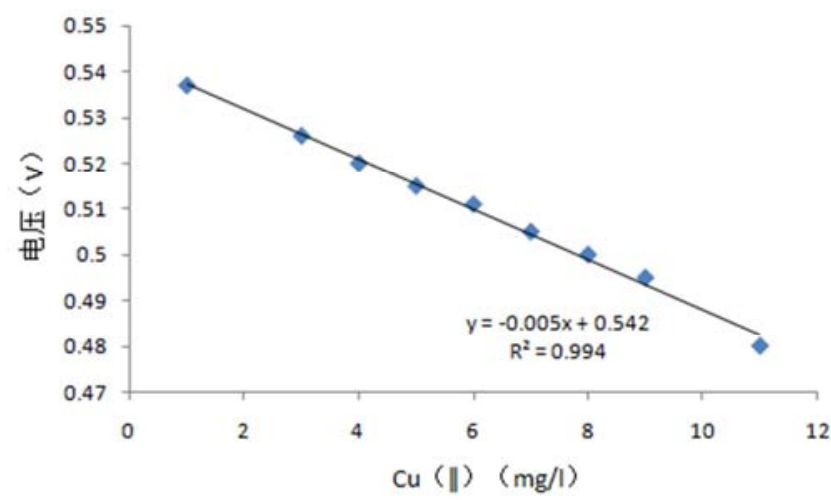

图5（a）30min电压的变化趋势图。

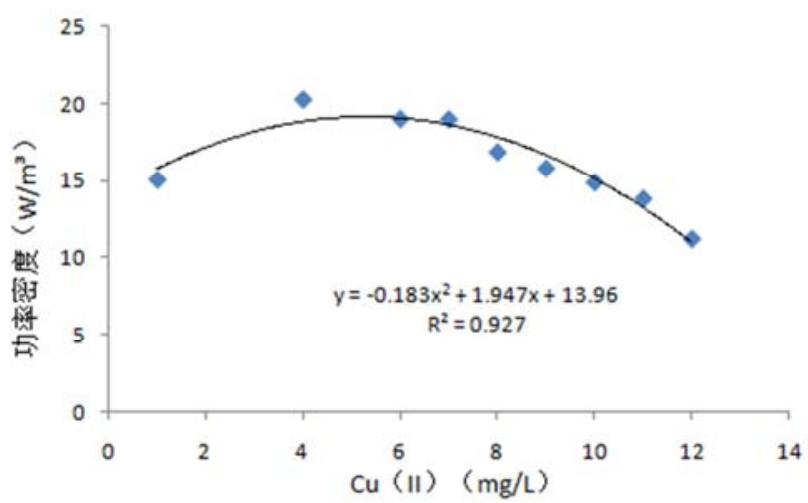

图5（b）功率密度的变化趋势图。

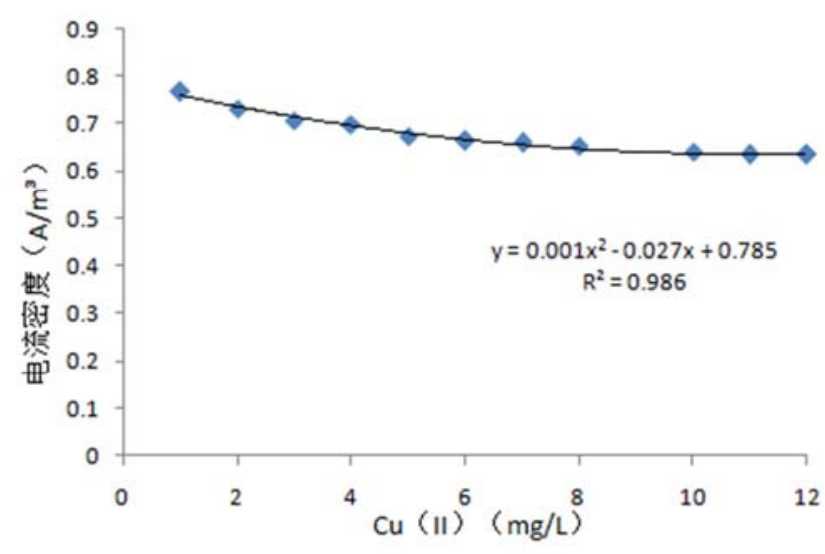

图5（c）电流密度的变化趋势图。

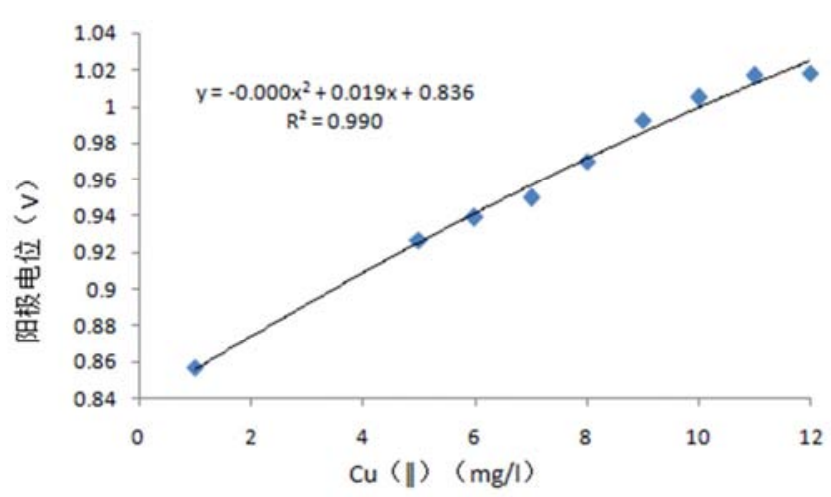

图5（d）阳极电位的变化趋势图。

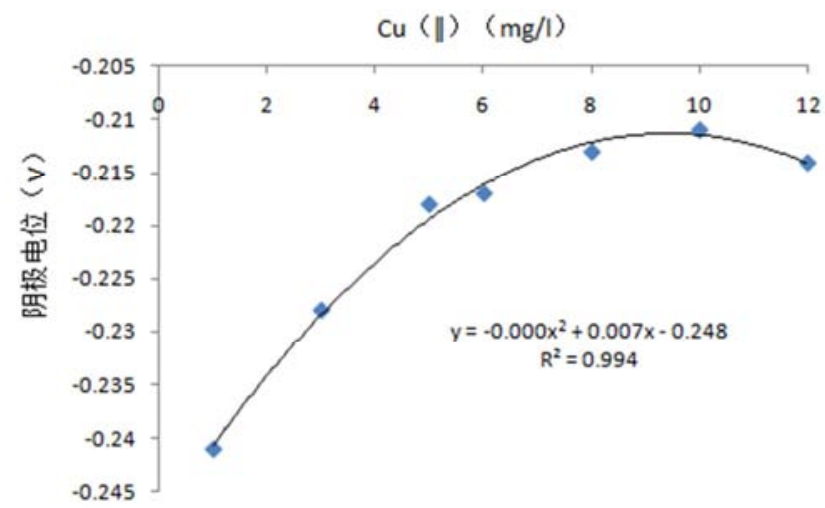

图5（e）阴极电位的变化趋势图。 


\section{PH对表征的影响}

在对重金属传感器进行实验的过程中, 为了研究进水 $\mathrm{PH}$, 对其电化学表征的影响, 本实验配制 4 个不同的PH值 来观测其电化学参数的变化, 进行极化曲线和功率密度曲 线, 电极电位的测量, 其测量结果如下。

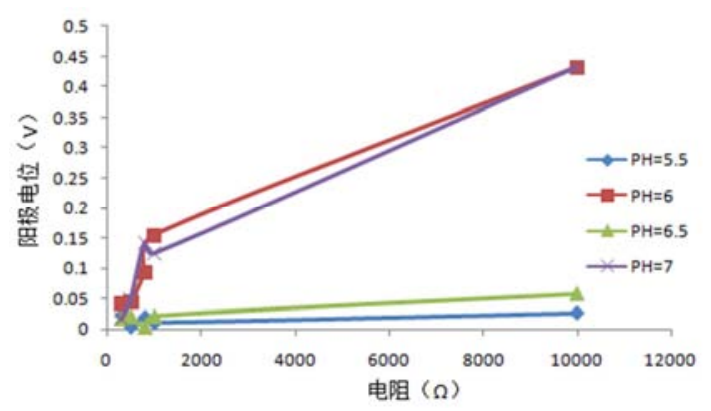

图6（a）阳极电位图。

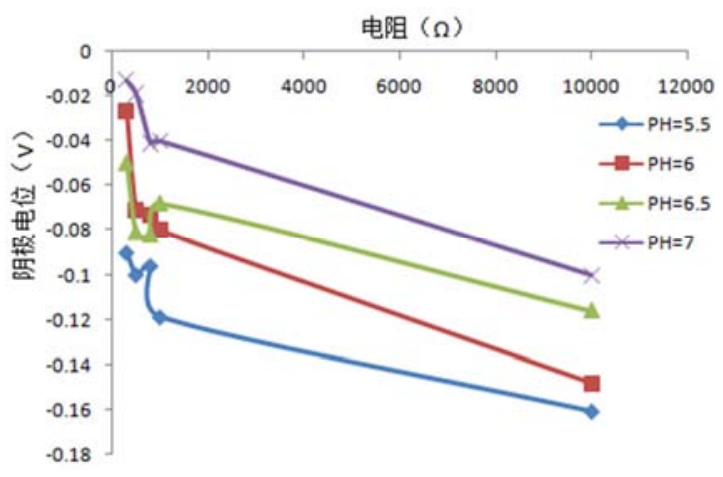

图6（b）阴极电位图。

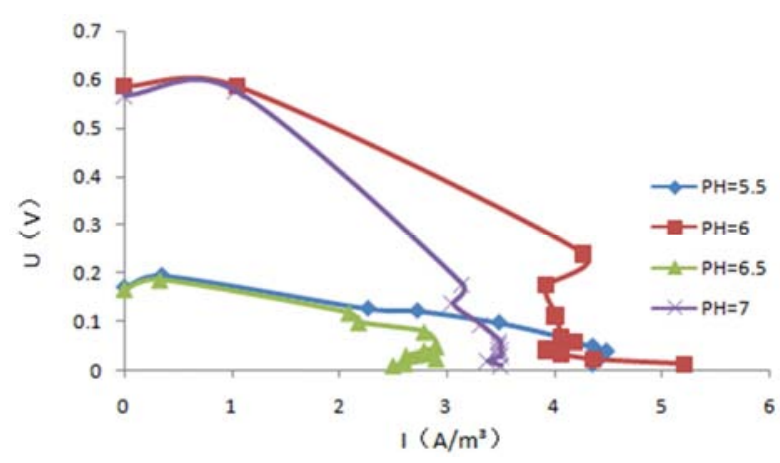

图6（c）极化曲线图。

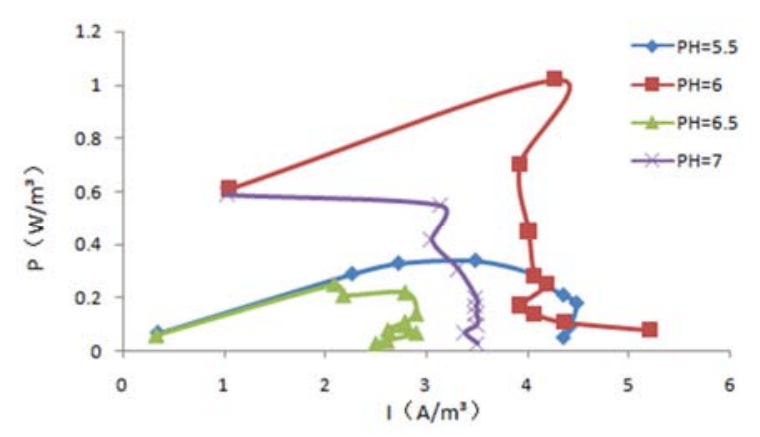

图6（d）功率密度曲线图。

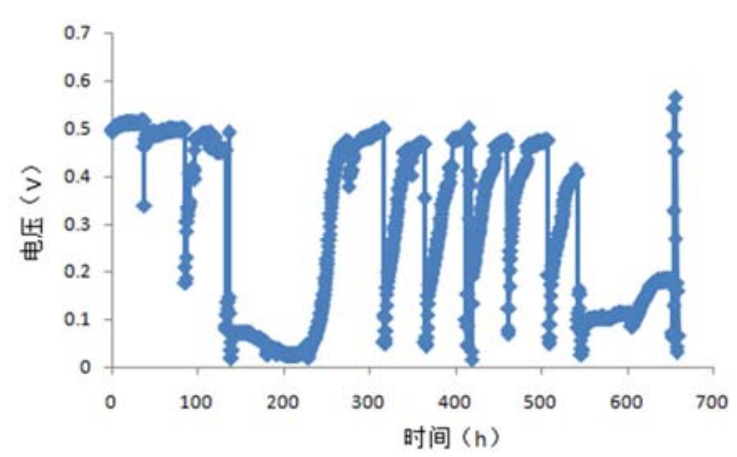

图6（e）30min电压图。

通过对一系列电化学参数的测量, 发现将测得的数值 带入 2.3 电化学参数的表征趋势线, 对比其与趋势线的离 散程度, 可以得出当进水PH值发生变化时, 对功率密度, 电流密度, 阴阳极电位的影响较大, 其变化的幅度也很大, 而实时电压变化的比较稳定, 经过对比, 得出 $\mathrm{PH}=6-6.5$ 这个区间, 各个参数的波动较小, 传感器运行稳定。

\section{5. 结论}

本实验, 通过改变铜离子浓度梯度, 来观察电化学参 数的响应, 通过测量实时电压, 功率密度, 电流密度, 阴 极电位, 阳极电位, 作为整个实验过程中的变量, 得出, 除了实时电压呈现线性的响应外, 其余的表征, 都呈现 $X^{2}$ 的响应, 此外还进行了进水的COD, 对于表征影响的实验, 可知, 当 $\mathrm{PH}=6-6.5$ 时, 各个表征的响应最稳定, 最具有实 际意义, 在整个实验的过程中, 发现微生物燃料电池可以 作为生物传感器中探测重金属浓度的检测仪器, 不仅解决 了, 限制其发展的瓶颈, 并且利用其自身的特点, 开阔了 实际应用, 为微生物燃料电池的发展提供新的探寻思路。

\section{参考文献}

[1] Y. V. Nancharaiaha, b, 爪, S. Venkata Mohan c, P. N. L. Lens Metals removal and recovery in bioelectrochemical systems: A review xxx (2015) xxxxxx.

[2] Yan Li, Yining Wu, SampadaPuranik, Yu Lei , Timothy Vadas, Baikun Li Metals as electron acceptors in single-chamber microbial fuel cells 269 (2014) 430-439.

[3] Modin 0., Wang X., Wu X., et al. Bioelectrochemical recovery of $\mathrm{Cu}, \mathrm{Pb}, \mathrm{Cd}$, and $\mathrm{Zn}$ from dilute solutions. (2012) 235 - 236, 291-297.

[4] Carole Abourached, TuncCatal 1, Hong LiuEfficacy of single-chamber microbial fuel cells for removal of cadmium and zinc with simultaneous electricity production 51(2014) 288-233. 
[5] Choi, C. , Hu, N. ,. The modeling of gold recovery from tetrachloroauratewastewater using a microbial fuel cell. Bioresour. Technol. 133, (2013) $589-598$.

[6] Zhihao Lu, Dingming Chang, Jingxing Ma, Guangtuan Huang, LankunCai, LehuaZhangBehavior of metal ions in bioelectrochemical systems: A review275 (2015) $243 \mathrm{e} 260$.

[7] Wang Z., Lim B. , Choi C. Removal of $\mathrm{Hg} 2+$ as an electron acceptor coupled with power generationusing a microbial fuel cell. Bioresource Technology, 2011, $102(10): 6304-6307$.

[8] Praveena Gangadharan, Indumathi M. Nambi $\Uparrow$, Jaganathan Senthilnathan Liquid crystal polaroid glass electrode from e-waste for synchronizedremoval/recovery of $\mathrm{Cr}+6$ fromwastewater by microbial fuel cel1195 (2015) $96-101$.

[9] Li H., Feng Y., Zou X., et al. Study on microbial reduction of vanadium matallurgical waste water. Hydrometallurgy, 2009, $99(1-2): 13-17$.

[10] Y. Zhang, L. Yu, D. Wu, L. Huang, P. Zhou, X. Quan, G. Chen, Dependency of simultaneous $\mathrm{Cr}(\mathrm{VI}), \mathrm{Cu}(\mathrm{II})$ and $\mathrm{Cd}$ (II) reduction on the cathodes of microbialelectrolysis cells self-driven by microbial fuel cells, J. Power Sources 273(2015) $1103-1113$
[11] Tandukar M., Huber S. J., Onodera T., et al. Biological Chromium(VI) Reduction in the Cathode of a Microbial Fuel Cell. Environmental Science \& Technology, 2009, $43(21): 8159-8165$.

[12] Tao H., Liang M. , Li W., et al. Removal of copper from aqueous solution by electrodeposition in cathode chamber of microbial fuel cell. Journal of Hazardous Materials, 2011, $189(1-2): 186-192$.

[13] Jiseon You a, X. Alexis Walter a, John Greenmana, b, Chris Melhuish a, IoannisIeropoulosStability and reliability of anodic biofilms under different feedstock conditions: Towards microbial fuel cell sensors6 (2015) $43-50$.

[14] SiiriVelling, Toomas TennoDifferent calibration methods of a microbial BOD sensor for analysis of municipal wastewaters141 (2009) $233-238$.

[15] Nienke Elisabeth Stein a, b, c, 1,2, Hubertus M. V. Hamelers a, c, 1, Gerrit van Straten b, 2, Kare1 J. Keesman0n-1ine detection of toxic components using a microbial fuel cell-based biosensor22 (2012) 1755 1761.

[16] SHEN Y J, LEFEBVRE 0, TAN Z, et al. Microbial fuel-cell-based toxicity sensor for fast monitoring of acidic toxicity [J]. Water SciTechnol, 2012, 65 (7) : 1223-1228. 